\title{
Plasma free captopril concentrations during short and long term treatment with oral captopril for heart failure
}

\author{
T R D SHAW, * F M DUNCAN,† B C WILLIAMS, † E CRICHTON, † A THOMSON, * \\ J R E DAVIS,† M RADEMAKER,^ C R W EDWARDS† \\ From the Departments of ${ }^{\star}$ Cardiology and + Medicine, Western General Hospital, Edinburgh
}

SUMMARY Plasma free captopril concentrations and haemodynamic response to captopril were studied in 20 patients with severe chronic heart failure. A $25 \mathrm{mg}$ oral dose of captopril produced a $36 \%$ reduction in systemic vascular resistance, with individual responses varying from $13 \%$ to $64 \%$. Mean systemic pressure fell by $20 \%$ and cardiac output rose $28 \%$. The absorption of captopril was rapid. Peak plasma free captopril concentration occurred at 45 minutes after the dose and was followed by a smaller second peak. Peak plasma free captopril concentrations varied more than 20 -fold but did not correlate with the maximal reduction in systemic vascular resistance. Elimination half life was seven hours. Fourteen patients were restudied after 1-2 months of captopril treatment and 12 showed symptomatic benefit. There was a sustained improvement in haemodynamic state and in non-invasive indices of myocardial function. During long term treatment the predose plasma free captopril concentration correlated well with dosage, but steady state captopril concentrations did not show a significant relation with haemodynamic response. On a dosage regimen of 25-50 mg three times daily the morning predose plasma free captopril concentration and plasma renin activity were relatively low and suggested that maximal inhibition of the renin-angiotensin system was not maintained throughout the dosage interval.

Captopril, a vasodilator which acts by inhibiting conversion of angiotensin I to angiotensin II, has been shown to benefit patients with chronic severe heart failure. ${ }^{1}$ The response to captopril varies appreciably between subjects, but the reasons for this are not fully understood. Measurement of plasma concentrations of captopril has been difficult because of the highly reactive thiol group in the captopril molecule. A radioimmunoassay for captopril has been developed, ${ }^{2}$ using antibodies to a captopril- $N$-ethylmaleimide complex, and we have used this assay to study the relation between plasma free captopril concentrations, haemodynamic responses, and plasma renin activity.

Patients and methods

STUDY POPULATION

Twenty patients (mean age 62.4 (range $47-71$ ) years) were studied, all of whom had severe left ventricular

Requests for reprints to Dr T R D Shaw, Department of Cardiology, Western General Hospital, Edinburgh EH4 2XU.

Accepted for publication 19 March 1985 myocardial impairment due to ischaemic heart disease in 13 and cardiomyopathy in seven. Nine had an associated valve abnormality and three mild hypertension. Each patient had continued to have cardiac symptoms at rest or with mild activity despite treatment with digoxin and frusemide (mean dose 188 (range $80-500) \mathrm{mg} /$ day). All patients were taking a diet without added salt. Potassium supplements (seven patients) and potassium retaining agents (13 patients) were withdrawn when captopril treatment began.

SHORT TERM RESPONSE

Each patient was given an initial dose of $25 \mathrm{mg}$ captopril dissolved in $150 \mathrm{ml}$ water. Haemodynamic measurements were made at 30,15 , and 0 minutes before this dose and for four hours (10 patients) or $1 \frac{1}{2}$ hours (10 patients) thereafter. Patients remained supine throughout the study period and for at least one hour before control recordings. They had fasted overnight and had not taken other medications on the day of study. A balloon flow directed catheter was used to record right atrial and pulmonary artery pres- 
sures and the cardiac output. Cardiac output was measured by indicator dye dilution (eight patients) or thermodilution (12 patients). Systemic pressure was recorded with a sphygmomanometer and arm cuff. Changes for all haemodynamic variables were measured at the time of each individual's maximal change in systemic vascular resistance.

\section{LONG TERM RESPONSE}

Patients were restudied at $1-2$ months after beginning captopril treatment. Dosage had been adjusted until symptomatic hypotension occurred or until a maximum dosage of $450 \mathrm{mg} /$ day (12 patients) or $150 \mathrm{mg}$ / day (eight patients) was reached. Haemodynamic measurements, plasma free captopril concentrations, and plasma renin activity were recorded at three intervals over 30 minutes as in the control period described above. The last captopril dose was given 4-6 hours before the repeat study.

Left ventricular function was assessed by nuclear ventriculography and echocardiography before captopril treatment and at repeat study 1-2 months later. Patients underwent exercise testing on a treadmill using the Bruce protocol modified to include an initial lower stage of $1.5 \mathrm{kph}$ at an $8^{\circ}$ incline: a practice run had been given.

\section{ASSAY OF PLASMA FREE CAPTOPRIL CONCENTRATION}

For the radioimmunoassay of captopril $10 \mathrm{mg}$ $\mathrm{N}$-ethylmaleimide was added to $5 \mathrm{ml}$ plasma separated in a refrigerated centrifuge immediately after withdrawal of the blood sample. The radioimmunoassay technique has been described elsewhere. ${ }^{2}$ The sensitivity of the assay is $2 \mathrm{ng} / \mathrm{ml}$ and the interassay coefficient of variance is $\mathbf{7 . 5 \%}$.

\section{PLASMA RENIN ACTIVITY}

Plasma renin activity was measured using the technique of Drury and Edwards. ${ }^{3}$ The range for normal supine subjects is $0.3-1.5 \mathrm{ng} / \mathrm{ml} / \mathrm{h}$. The coefficients of variance were $10 \%$ (intra-assay) and $18 \%$ (interassay).

\section{Results}

\section{SHORT TERM RESPONSE}

Haemodynamic response-Table 1 shows haemodynamic changes found after the first $25 \mathrm{mg}$ dose of captopril. Systemic vascular resistance fell by $36 \%$ to reach a mean level just above the upper limit of the normal range. The percentage reduction in systemic vascular resistance for individual subjects ranged from $13 \%$ to $64 \%$.

Plasma free captopril-Captopril was absorbed rapidly with the peak concentration at 45 minutes after the dose. The rise in plasma free captopril coincided with the fall in systemic vascular resistance and was followed closely by an increase in plasma renin activity. Figure 1 shows the time profiles of changes in systemic vascular resistance, plasma free captopril concentration, and plasma renin activity in 10 patients. The areas under the four hour free captopril absorption curves varied from 44 to $689 \mathrm{mg} / \mathrm{ml} / \mathrm{h}$ (mean (SD) 352(237)).

Peak plasma free captopril concentrations varied appreciably, but there was no significant correlation (Fig. 2) between the maximal percentage reduction in systemic vascular resistance and the peak plasma free captopril concentration $(r=0.28)$ or its $\log$ concentration $(r=0.40)$.

A small second peak of plasma free captopril concentration was seen in 16 of the 18 patients who had plasma free captopril concentrations measured up to four or 24 hours after the dose. The mean secondary rise was $38.1 \mathrm{mg} / \mathrm{ml}$ from a mean preceding concentration of $56.3 \mathrm{mg} / \mathrm{ml}$. Of the eight subjects in whom plasma free captopril was measured for 24 hours, two had slow absorption with peak captopril concentrations at 90 and 240 minutes after the dose. The other six patients showed a rapid absorption of captopril (peak concentration $<60$ minutes after the dose); a small second peak was apparent at two hours in these subjects (Fig. 3). The elimination rate of free captopril, measured from five to 24 hours after the dose in these six subjects, was seven hours.

Table 1 Short term haemodymamic response to $25 \mathrm{mg}$ oral captopril in 20 patients. Values are mean (SD) unless stated otherwise

\begin{tabular}{|c|c|c|c|c|}
\hline & $\begin{array}{l}\text { Before captopril } \\
p\end{array}$ & $\begin{array}{l}\text { After initial } 25 \mathrm{mg} \\
\text { oral dose }\end{array}$ & $\%$ Change & $\begin{array}{l}p \text { value (paired } \\
t \text { test) }\end{array}$ \\
\hline $\begin{array}{l}\text { Systemic vascular resistance }\left(\text { dyn } \mathrm{s} \mathrm{cm}^{-5}\right) \\
\text { Mean systemic pressure }(\mathrm{mm} \mathrm{Hg}) \\
\text { Cardiac output }(1 / \mathrm{min}) \\
\text { Pulmonary end diastolic pressure }(\mathrm{mm} \mathrm{Hg}) \\
\text { Mean right atrial pressure }(\mathrm{mm} \mathrm{Hg}) \\
\text { Heart rate (beats/min) } \\
\text { Plasma renin activity }(\mathrm{ng} / \mathrm{ml} / \mathrm{h})\end{array}$ & $\begin{array}{l}2350(788) \\
91.3(14.2) \\
2.80(0.58) \\
30.5(7.3) \\
13.2(4.4) \\
75.7(10.4) \\
5.70(6.23)\end{array}$ & $\begin{array}{l}1503(693) \\
73.3(14.7) \\
3.57(0.81) \\
25.1(6.8) \\
11.4(4.2) \\
75.5(12.5) \\
34.58(33.21)\end{array}$ & $\begin{array}{l}-36.0 \\
-19.7 \\
+27.5 \\
-17.7 \\
-13.6 \\
-0.3 \\
+506.6\end{array}$ & $\begin{array}{l}<0.001 \\
<0.001 \\
<0.001 \\
<0.001 \\
<0.01 \\
\text { NS } \\
<0.001\end{array}$ \\
\hline
\end{tabular}




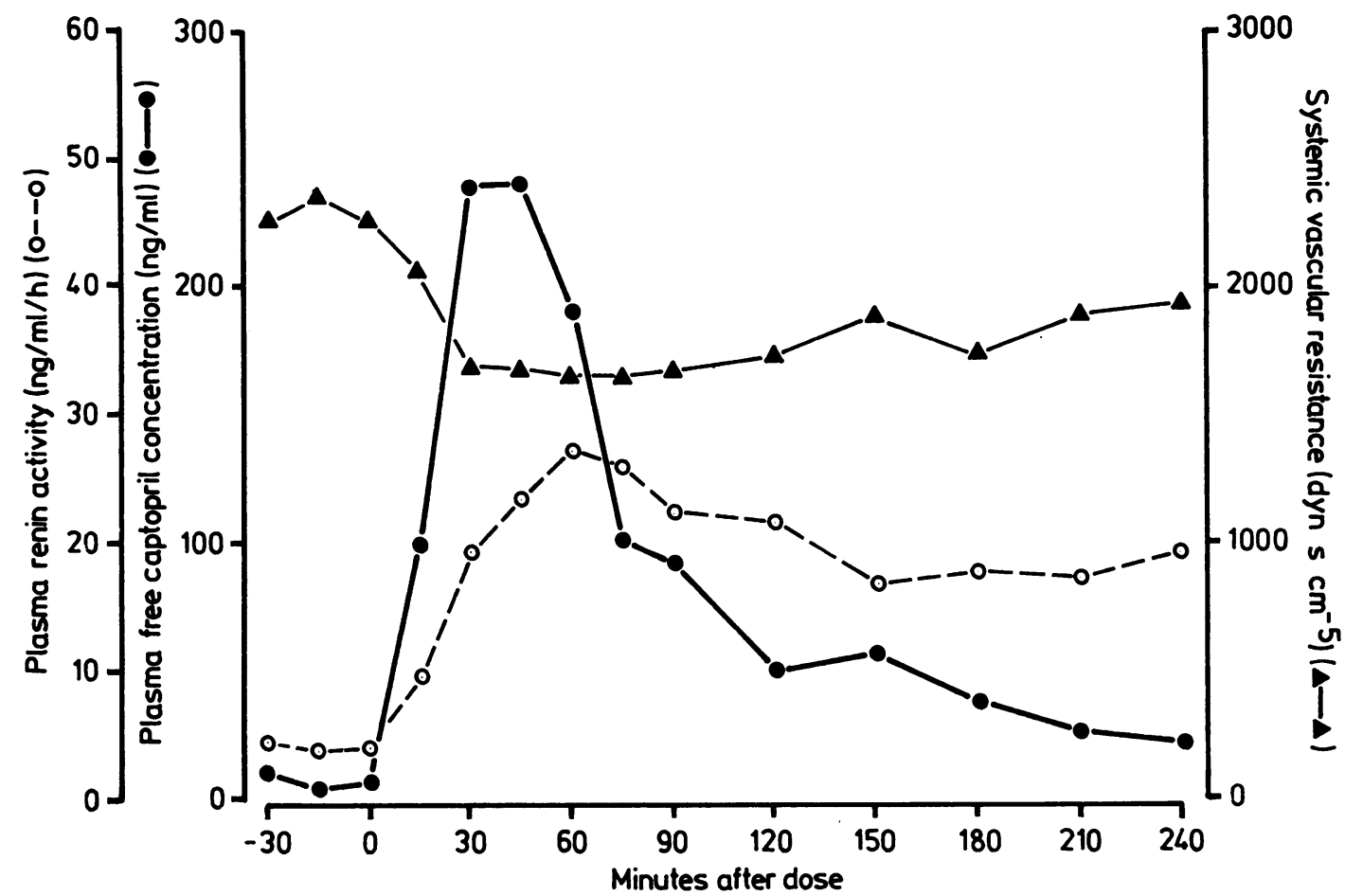

Fig. 1 Mean plasma free captopril concentration $(\Theta)$, systemic vascular resistance $(\Delta)$, and plasma renin activity $(O)$ measured before and for four hours after a $25 \mathrm{mg}$ oral dose of captopril $(n=10)$.

LONG TERM RESPONSE

Four patients, all of whom had control plasma renin activity $>10 \mathrm{ng} / \mathrm{ml} / \mathrm{h}$, did not tolerate captopril treat-

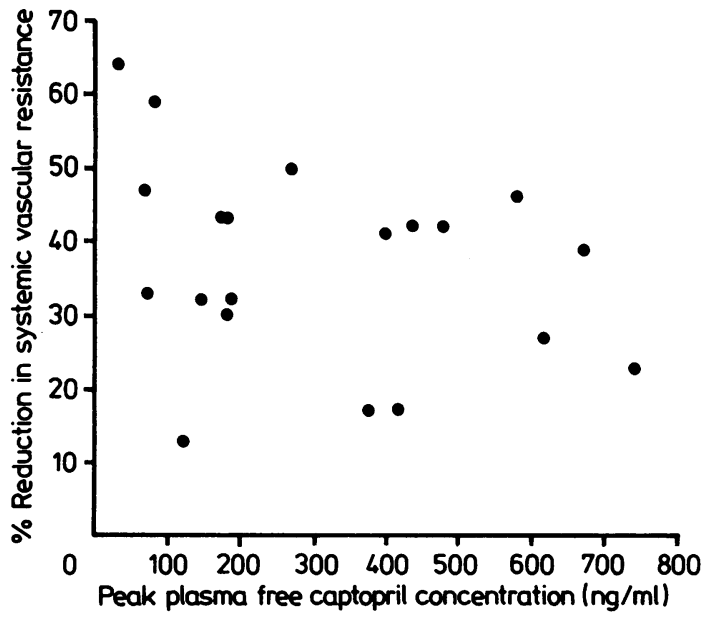

Fig. 2 Relation between percentage reduction in systemic vascular resistance and peak plasma free captopril concentration in 20 patients with severe chronic heart failure. ment, three because of lightheadedness or syncope and one because of taste disturbance. One patient with three vessel coronary artery disease died suddenly after 17 days of captopril treatment. A further patient, who had mitral stenosis and myocardial impairment, showed progressive deterioration: he died nine days after captopril treatment ended. Fourteen patients were therefore available for repeat study. Twelve of these patient showed symptomatic improvement with captopril treatment (Fig. 4).

Haemodynamic response-Table 2 summarises the haemodynamic and non-invasive variables before and after 1-2 months of captopril treatment.

Plasma free captopril-The dosage of captopril at repeat study ranged from $75 \mathrm{mg} /$ day to $450 \mathrm{mg} /$ day. The mean plasma concentrations for daily dosages of $75(\mathrm{n}=4), 150(\mathrm{n}=7)$, and $300-450 \mathrm{mg}(\mathrm{n}=3)$ were 46 , 73 , and $233 \mathrm{ng} / \mathrm{ml}$ respectively. There was a significant correlation between dosage and free captopril concentration $(r=0.77, p<0.01)$.

As with the short term response, no correlation existed between percentage reduction in systemic vascular resistance and plasma free captopril concentration $(r=0 \cdot 09)$.

Plasma free captopril concentration and plasma 


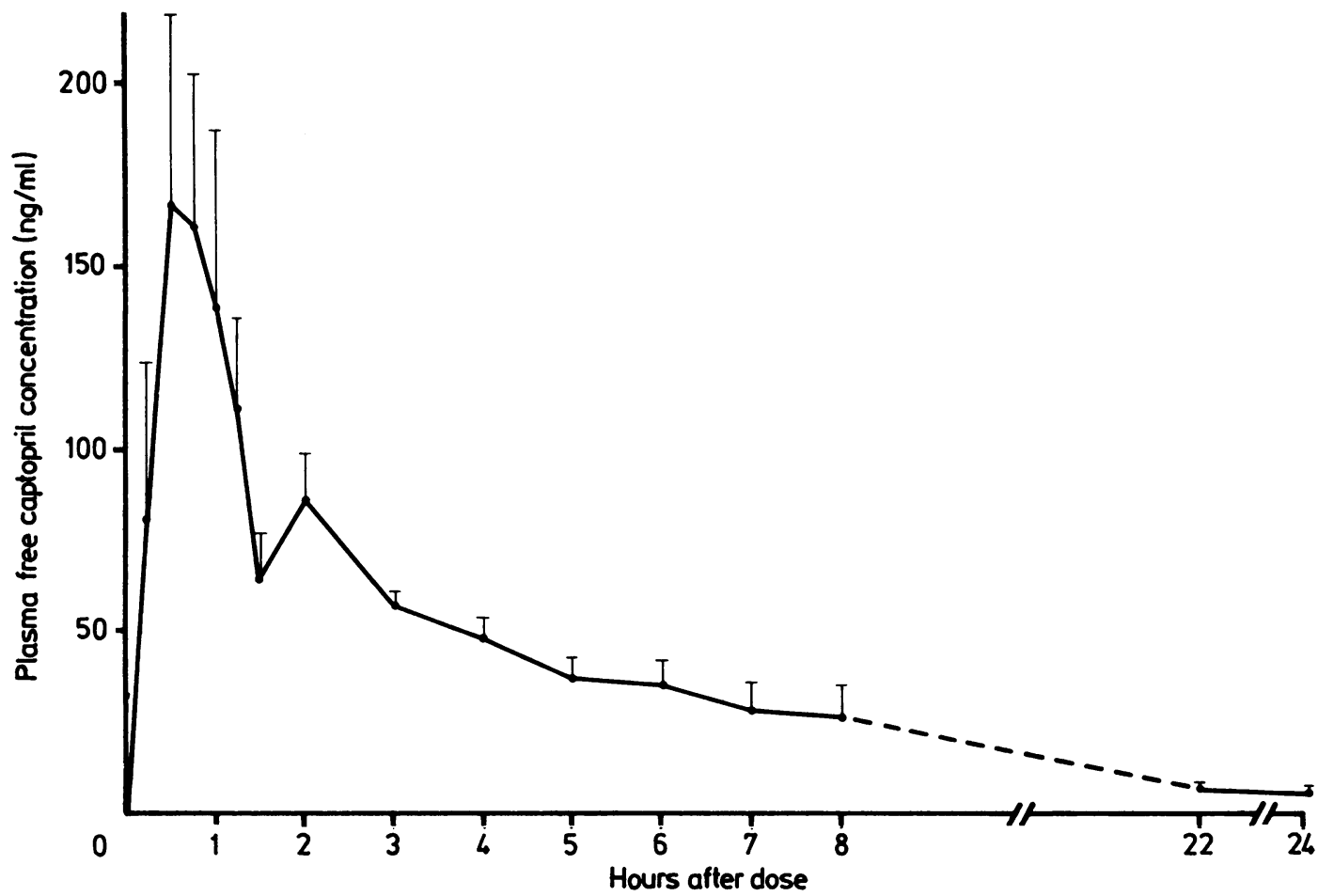

Fig. 3 Mean (SEM) plasma free captopril concentrations during 24 hours after a $25 \mathrm{mg}$ oral dose of captopril in six patients who showed rapid absorption (peak plasma free captopril $\leqslant 60$ minutes).

renin activity were measured throughout an eight hour dose interval during long term treatment in six patients. Two were receiving $25 \mathrm{mg}$ three times daily and four $50 \mathrm{mg}$ three times daily Figure 5 shows the results. The predose $(0900 \mathrm{~h})$ plasma free captopril concentration was low, and there was a pronounced rise in drug concentration after absorption of the dose, with a small second peak at six hours. Plasma renin activity showed a further increase after the dose.

\section{Discussion}

In individual cardiac patients the haemodynamic and symptomatic response to captopril can vary from minimal to very substantial. Our results, like other studies, 145 show an overall moderate degree of improvement in symptoms, resting haemodynamic indices, and non-invasive indices of cardiac function, and they confirm the wide range of individual responses. Since this was an open study and a placebo period was not included the changes in symptom status have to be interpreted with caution. Similar benefits from captopril in heart failure have, however, been found in double blind controlled studies. ${ }^{6-8}$

Wide differences in peak plasma free captopril concentration were found but did not correlate with maximal percentage change in systemic vascular resistance. Plasma also contains captopril linked to the plasma proteins, cysteine and glutathione, and captopril molecules linked together as disulphide bond dimers, ${ }^{910}$ but these compounds are not thought to be biologically active. The lack of relation between maximal response and peak plasma free captopril concentration after a $25 \mathrm{mg}$ oral dose may be explained by the flat dose-response relation found in incremental dose studies when captopril dose exceeded $6.25 \mathrm{mg}$. There was also no correlation between captopril concentration and long term response, and our results do not show any evidence that measurement of plasma free captopril concentration would be useful in monitoring response.

The early peak concentrations of plasma free captopril indicate that absorption of captopril occurred rapidly in the fasting patients in this study. This coincided with a rapid onset of action. The pronounced variation in the peak plasma free captopril concentrations and in the area under the four hour curves could arise from several factors including impairment of the extent of absorption due to the presence of cardiac failure, degradation or binding of captopril within the gastrointestinal tract, differential metabolism, or differences in the volume of drug distribution. McKins- 
164

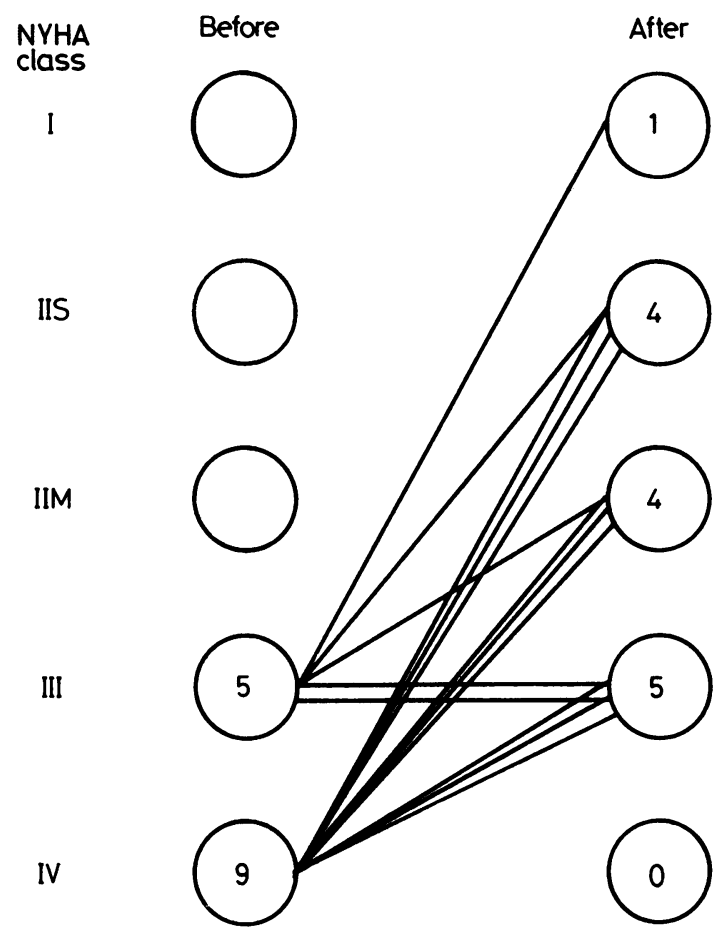

Fig. 4 Symptom status (NYHA class) in the 14 patients before and after long term treatment with captopril.

try et al gave oral doses of isotopically labelled captopril to normal subjects and estimated total absorption to be $68 \%$ (SD 9\%), but in the first few hours after the dose less than half of the total plasma radioactivity was associated with free captopril and there was extensive conversion to the inactive forms. ${ }^{11}$ Cody $e t a l$ also found that the concentration of bound captopril was higher than the concentration of free captopril during 0-8 hours after an oral dose. ${ }^{12}$ They suggested that the bound forms might constitute a reservoir for the active drug.

A small second peak in the absorption curve was

Table 2 Long term response to captopril treatment in 14 patients. Values are mean (SD) unless stated otherwise

\begin{tabular}{|c|c|c|c|c|}
\hline & $\begin{array}{l}\text { Before captopril } \\
\text {. }\end{array}$ & $\begin{array}{l}\text { After 1-2 months' } \\
\text { treatment }\end{array}$ & $\%$ Change & $\begin{array}{l}p \text { value (paired } \\
t \text { test) }\end{array}$ \\
\hline $\begin{array}{l}\text { Systemic vascular resistance }\left(\text { dyn s } \mathrm{cm}^{-5} \text { ) }\right. \\
\text { Mean systemic pressure (mm } \mathbf{H g}) \\
\text { Cardiac output (1/min) } \\
\text { Pulmonary end diastolic pressure }(\mathrm{mm} \mathrm{Hg}) \\
\text { Mean right atrial pressure (mm } \mathbf{H g}) \\
\text { Heart rate (beats/min) } \\
\text { Plasma renin activity }(\mathrm{ng} / \mathrm{ml} / \mathrm{h}) \\
\text { Exercise duration (min) } \\
\text { Echocardiographic fractional shortening (\%) } \\
\text { Nuclear ejection fraction (\%) }\end{array}$ & $\begin{array}{l}2397(768) \\
92.7(14.8) \\
2.88(0.61) \\
30.1(6.3) \\
11.8(3.3) \\
76.6(9.3) \\
2.6(2.9) \\
2.64(3.03) \\
10.8(3.6) \\
24.1(7.0)\end{array}$ & $\begin{array}{l}1926(635) \\
88.7(10.8) \\
3.49(0.80) \\
24.4(5.5) \\
9.6(3.5) \\
72.3(9.5) \\
8.3(4.3) \\
4.48(3.26) \\
14.0(3.8) \\
34.0(11.3)\end{array}$ & $\begin{array}{l}-19 \cdot 6 \\
-4 \cdot 3 \\
+21 \cdot 2 \\
+18 \cdot 9 \\
-18 \cdot 6 \\
-5 \cdot 6 \\
+219(n=11) \\
+70 \\
+30 \\
+41(n=10)\end{array}$ & $\begin{array}{l}<0.001 \\
\text { NS } \\
<0.01 \\
<0.02 \\
\text { NS } \\
\text { NS } \\
<0.01 \\
<0.02 \\
<0.01 \\
<0.05\end{array}$ \\
\hline
\end{tabular}

Fig. 5 Mean plasma free captopril concentrations ( $\odot$ ) and plasma renin activity $(O)$ in six patients studied duaing a dosage interval while receiving long term treatment with captopril.

found in most of our patients. This may be due to enterohepatic recirculation. This second peak was not large and was associated with only a small and statistically insignificant secondary decrease in systemic vascular resistance at $\mathbf{1 8 0}$ minutes after the dose (Fig. 1). Levine $e t$ al also observed a small secondary peak in response. ${ }^{13}$ The true elimination rate of a drug is often difficult to establish as the absorption and distribution phases can continue until the plasma drug concentration is too low for the sensitivity of the assay. This second peak complicates the estimation of the elimination rate of plasma free captopril, but when taken between 5 and 24 hours after the dose we found the log concentration time plot to be linear and the elimination half life to be seven hours.

We found that throughout an eight hour dose interval during long term treatment $(25-50 \mathrm{mg}$ three times daily) the plasma free captopril concentration was maintained at levels which had provided some 
haemodynamic response in the acute study. Plasma renin activity remained increased but showed a further increase after the dose. This suggests that a thrice daily dosage schedule is adequate for maintaining a haemodynamic response but possibly not at a maximal level throughout the eight hour period at this dosage. Larger doses of captopril are, however, associated with a greater incidence of side effects, and for this reason dosages of $>150 \mathrm{mg} /$ day are now seldom used.

\section{References}

1 Romankiewicz JA, Brogden RN, Heel RC, Speight TM, Avery GS. Captopril: an update review of its pharmacological properties and therapeutic efficacy in congestive heart failure. Drugs 1983; 25: 6-40.

2 Duncan FM, Martin VI, Williams BC, Al-Dujaili EAS, Edwards CRW. Development and optimisation of a radioimmunoassay for plasma captopril. Clin Chim Acta 1983; 131: 295-303.

3 Drury PL, Edwards CRW. Studies on the cryoactivation of human renin. Clin Chim Acta 1981; 113: 319-23.

4 Cohn JN, Levine TB. Angiotensin-converting enzyme inhibition in congestive heart failure: the concept. $A m \mathcal{F}$ Cardiol 1982; 49: 1480-3.

5 Dargie HJ, Ball SG, Atkinson AB, Robertson JIS. Converting enzyme inhibitors in hypertension and heart failure. Br Heart $\mathcal{F}$ 1983; 49: 305-8.
6 Kramer B, Massie B, Topic N. Controlled trial of captopril for heart failure: effects on hemodynamics, scintigraphy and exercise tolerance [Abstract]. Am $\mathcal{F}$ Cardiol 1982; 49: 925.

7 Captopril Multicenter Research Group. A placebo controlled trial of captopril in refractory chronic congestive failure. 3 Am Coll Cardiol 1983; 2: 755-63.

8 Cleland JGF, Dargie HJ, Robertson JIS, Ball SG, Hodsman GP. The use of captopril in the management of cardiac failure. Scott Med f 1984; 29: 129-30.

9 Wong KK, Lan SJ, Migdalof BH. In vitro biotransformations of $\left[{ }^{14} \mathrm{C}\right]$-captopril in the blood of rats, dogs and humans. Biochem Pharmacol 1981; 30: 2643-50.

10 Kripalani KJ, Meeker FS Jr, Dean AV, McKinstry DN, Migdalof $\mathrm{BH}$. Biotransformation of ${ }^{14} \mathrm{C}$-captopril in hypertensive patients and normal subjects [Abstract]. Fed Proc 1980; 39: 307.

11 McKinstry DN, Singhui SM, Kripalani KJ, Willard DA, Migdalof BH. Kinetics of captopril in healthy subjects. In: Brunner HR, Gross F, eds. Recent advances in hypertension therapy: captopril. Amsterdam: Excerpta Medica, 1981:4-14.

12 Cody RJ, Covit A, Schaer G, Williams G. Captopril pharmacokinetics and the acute hemodynamic and hormonal response in patients with severe chronic congestive heart failure. Am Heart $\mathcal{F} 1982$; 104: 1180-3.

13 Levine TB, Franciosa JA, Cohn JN. Acute and longterm response to an oral converting-enzyme inhibitor, captopril, in congestive heart failure. Circulation 1980; 62: 35-41. 